\title{
Unravelling structural fabric - a necessity for realistic rock mass characterisation for deep mine design
}

\author{
TG Carter Golder Associates Ltd., Canada \\ SF Rogers Golder Associates Ltd., Canada \\ JJL Taylor Golder Associates Ltd., Canada \\ J Smith Golder Associates Ltd., Canada
}

\begin{abstract}
In recent years, there has been a spate of quite unexpected major failures within surface and underground mines that have significantly compromised mine stability and resulted in sustained loss of production. In the majority of these cases, evidence suggests that incipient, weak, generally incoherent structural fabric within the rock mass played a significant role in influencing the failure development. With the trend towards underground mines going ever deeper, and many of the large open pits transitioning to block cave operations, more focus is needed on gaining better structural geological understanding of incipient rock mass fabric within and outside the mining block so that such failure risks can be minimised.

Current trends towards mine scale quantification of rock mass characteristics and development of local and regional scale discrete fracture network simulations, as basis for generation of synthetic rock mass models based on rigorous quantification of geological fabric assessments, is allowing better appreciation of the variability within a rock mass. However, comprehensive understanding of key elements of the geological fabric is often missing. This can lead, in worst case scenarios, to situations when the resulting models cannot be expected to capture the controlling mechanisms.

This paper presents several structural geology techniques that are not widely known, or even commonly applied, either for large deep open pit design studies or for deep high stress underground mining. These techniques have merit for aiding risk minimisation for deep excavation through improved insight.

Guidelines are provided for using fault striae data and applying stress inversion, slip tendency and critical stress evaluation approaches for advancing understanding of past and present day stress states - both key factors important to establishing the current stability state of major geologic structures transecting or bounding large surface or underground mining extraction blocks. Some techniques for estimating likely risk for inducing adverse slip on incipient geologic structures, potentially affected by mining, are also explored in the final sections of the paper.
\end{abstract}

\section{Introduction}

Unexpected, adverse, stress driven, structurally-controlled instability problems continue to be an issue of concern for deep mining projects, particularly as conventional underground mines go deeper and many deep open pits are transitioning to mega block cave operations.

Although in recent times, with application of advanced numerical modelling techniques, much greater comprehension is typically gained during routine mine design of how different mining sequences can create different interaction with regional stress conditions, little attention is still typically given to assessing the effects of stress rotation and redistribution on remobilising ancient incipient geological structure. Mostly, in the design stages of typical mining projects, and even into the operations stage, attention is focussed on first characterising the rock mass quality with Q (Barton et al. 1974) or with rock mass rating (RMR) (Bieniawski 1973; 1989) or with the geological strength index (GSI) (Hoek \& Marinos 2000; 
Marinos et al. 2005; Hoek et al. 2013) in order to develop appropriate Hoek-Brown envelopes (Hoek \& Brown 1980a; 1980b; Hoek \& Martin 2014) and then subsequently performing numerical modelling to evaluate the proposed mining sequence and verify the effectiveness of the chosen mining methods. Seldom, if ever, is a fully holistic overview analysis made in order to check whether the potential exists for adversely remobilising major non-ore displacing, off-seam fault structures. Seemingly, there is a widely held misconception that undertaking such analysis would be largely impractical without rafts of data, and typically would be so incredibly complex (requiring significant extra site investigation expenditure) as to not be of much value for advancing project understanding.

This paper attempts to dispel the myth that assessing fault reactivation characteristics is an unduly complex, time-consuming and expensive task. Several, relatively unknown, but yet quite rudimentary, structural geology techniques are introduced in this paper with the hope that more use will be made of these simple methods as a means for rapidly and cost-effectively assessing whether stress-driven structural problems might or might not become problematic. These techniques, which largely originated from within the earthquake engineering field of interpretive structural geology (Ramsay \& Lisle 2000; Pollard \& Fletcher 2005; Célérier et al. 2012), and which also have application for assessing the propensity for fault reactivation in a mining context, are rarely, if ever, applied as a step in the design process for developing a new deep mine, or for expansions of an existing mine footprint.

For any deep mine with high stresses or for any mine where significant extraction has occurred or is planned, such that a new hoop stress state will be developed around the mining block, the potential exists for rotating the ambient stress field to a new configuration. The methods outlined in this paper allow some assessment to be made of how adverse this rotational influence might become, and what its influence might be on pre-existing geological structure transecting or bounding the planned mining extraction zone.

Under extreme conditions, the possibility may exist that such rotation could be sufficient to adversely disrupt the stability of pre-existing geological structures, potentially leading to adverse shear reactivation. The propensity for reactivation to create damage in the underground situation will depend on the characteristics of the fault (width, planarity etc.) and its shear strength. Adverse shear mobilisation of dormant brittle faults with minimal gouge and significant undulation/asperity roughness can lead to the generation of significant seismicity. Similar magnitudes of shear reactivation of faults with major gouge infilling of low effective shear strength may only lead to localised dislocation, without inducing significant areal seismicity. Establishing the most probable response is when additional data becomes important. This paper, however, addresses only the first step in this process to definition of potential problem mechanisms.

The applicability of three techniques is specifically discussed in the context of using these suggested tools to better aid mine design. This can be achieved by identifying and characterising geological structures from the viewpoint of whether or not the structures might develop adverse re-activation characteristics as a consequence of adjacent mining. The three approaches and their suggested applicability context are as follows:

- Structural fabric dihedra (beachball) diagrams: for definition of probable re-activation stress orientations and possible energy release mechanisms.

- Slip tendency and dilation tendency stereonets: for estimating most probable orientation and magnitude of preferential shear dislocation or reduced confinement orientations conducive for fault re-activation.

- Critical stress Mohr circle plots: for assisting in the probabilistic assessment of potential risk for serious remobilisation of critically aligned geologic structures.

Each of these techniques is explained along with example plots and background references, allowing the more interested reader to delve deeper into their development and application. Guidelines for using fault striae data and for applying stress inversion approaches are included in the discussion around preparation of beachball plots as a basis for advancing understanding of past and current stress states. Understanding 
of both are key to establishing propensity for reactivating slip on pre-existing geological structures due to stress rotation and/or stress magnitude changes that may be induced by mining.

\section{Background}

Increasingly, mine design follows a three-step process:

1. An exploration evaluation phase (when geology, particularly ore genesis, is seriously considered).

2. A phase of geomechanical characterisation to assess and ascribe appropriate global rock mass strength parameters (essentially as a function of a downgraded index from the intact properties, aiming to account for the effect of structural fabric heterogeneity).

3. The actual design computations and analysis phase, generally involving application of empirical or numerical tools or a combination of both.

For many mining projects, little consideration is given to assessing the possible influence of structural geological features as part of this typical design process. It is no wonder, therefore, that surprises occasionally occur when, for example, in underground production, uncontrollable dilution starts to occur on some geological structure that was considered of minor importance, or stress-driven popping or bursting starts to initiate in areas away from zones of stoping, which were located in areas considered 'well outside' the zone of inferred mining influence.

Key geological data of importance to gaining an adequate understanding of controlling structure driving these types of instability problems does not seem to be regularly collected or evaluated. In fact, mostly the industry is unaware of the benefits that can be gained by appropriate use of simple structural geological tools, which if applied pro-actively could significantly improve insight and understanding of possible geological structural interactions and implications.

One recognisable issue that is gaining focus, and which ultimately may alert wider industry awareness, is that fault-controlled rockburst-style events of various magnitudes are increasingly being reported by the microseismic systems installed in many of the deepest mines. Such events are becoming more common and of increasing magnitude as mines go deeper and higher stresses become more and more controlling.

\section{$2.1 \quad$ Rock mass characterisation}

Industry often confuses characterisation (holistic review of rock mass properties) with simple classification (using a standard system/scale developed to interpret the characteristics of a rock mass). The well-known classification systems (Q, RMR, GSI and, to a lesser degree, rock mass index (RMi)) (Palmström 2000; 2005; 2009) are all predicated on characterising the rock mass almost solely on the basis of the medium scale fabric. Typically, the basis is some assessment of the influence that identified discontinuities play in reducing rock mass competence. The classifications include some assessment (visual or by measurement) to define the spacing and surface characteristics of the joints and some include a measure of the competence of the intact rock. Mostly these are then used in modelling or in empirical or analytical design approaches to assess mining layout sizing and sequencing issues. In essence, for this design step, the classifications define an effective degradation in rock block size and hence effective reduction of rock mass strength, scaled with respect to intact rock material strength.

Apart from the inclusion of an orientation de-rating to account for the potentially unfavourable geometry of the primary joint set with respect to the planned excavation geometry in the RMR classification (to attempt to reflect the essence of the problems illustrated in Figure 1) and a similar orientation adjustment included into the Mathews-Potvin empirical open stope calculation approach, (Mathews et al. 1981; Potvin et al. 1989), orientation and attitude of actual geological structure is not considered specifically in any of the classifications. In fact, true structural fabric is essentially ignored. Nevertheless, classifications have met with much success industry wide, as they allow ready numerical simplification of a complex blocky rock mass to something quantifiable; most users defining just a single number or range. Better 
representation can be achieved with possibly a normal or skewed probability distribution (Carter 1992); however, this level of detail in data assessment is rarely employed. Partially this is because, reality from actual tunnel mapping (Carter 2010; 2011), suggests that it is rare that a specific classification value or range representing block size/rock quality variability can be extrapolated for more than a few tens of metres along a drift or tunnel alignment due to real geological variability.

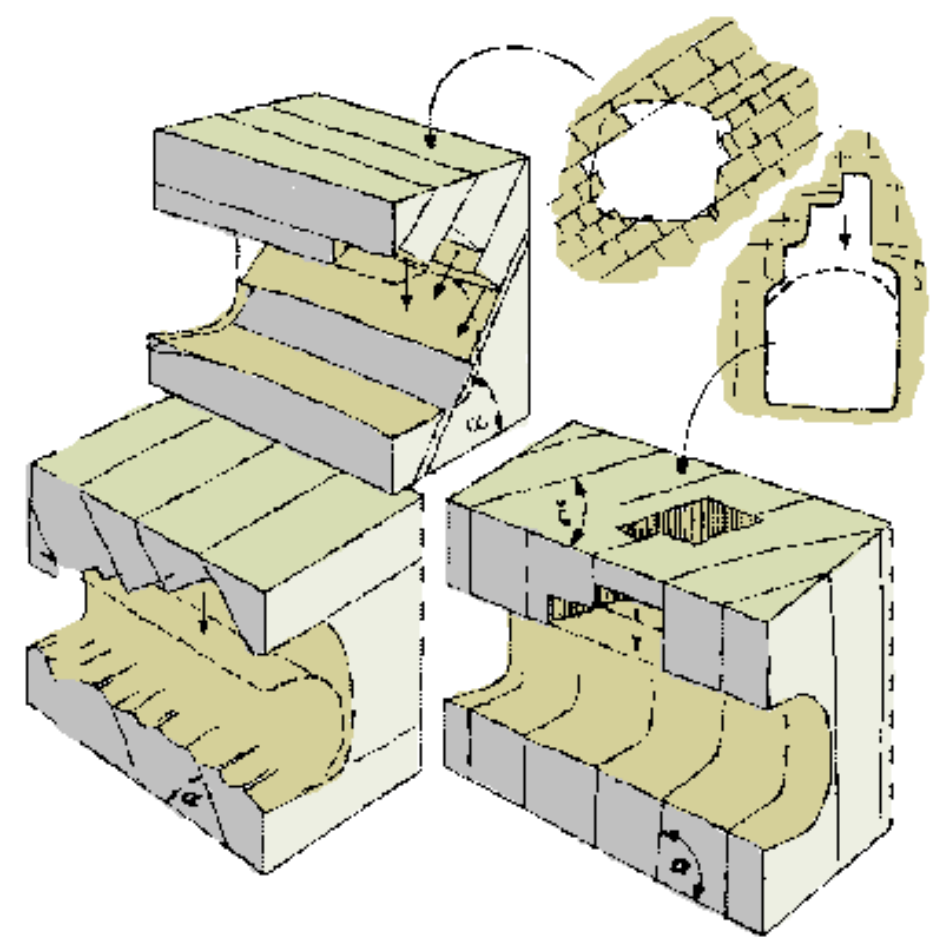

Figure 1 Characteristic influence of discontinuity attitude on tunnel stability

The pragmatic solution to this dilemma of misrepresentation is to 'domain' the rock mass for design purposes, subdividing the engineering structure (deep stoping block, open pit, tunnel and/or surface foundation etc.) into zones deemed of similar geological character, within each of which the classification assessment is considered to remain sufficiently consistent to allow use of a reliable single number or probability distribution per domain. Sometimes, but not consistently, domain boundaries get drawn along the trace of geological structures of note.

Geology has started at this stage to be given cursory consideration, and structure may now be taken more fully into consideration through stereonet plotting of discontinuity concentrations per domain. This is where design evaluations are often stopped though, still without any attempt being made to unravel the 'big picture' structural geological framework, even though it may exert a critical control on mineability.

The outcome of this is that for an increasing percentage of designs, often quite excellent numerical quantification of rock mass fabric variability is accomplished, but not infrequently virtually no attention has been given to gaining real understanding of overriding structural controls that created that variability.

\section{$2.2 \quad$ Structural control}

Experience from many mining projects worldwide that have experienced serious ground control problems show that what really controls large-scale ground behaviour is not the type of fabric variability which engineering classifications handle quite well. Rather, it is structural fabric influence and large-scale geology that actually controls major scale ground behaviour. Currently, industry-wide, we are at best only partially capturing this dependence, even with 'domained' classifications.

The fabric of the rocks within a project site (within, say, a several tens of kilometre square area that is characterised regionally, by, for example, even occasional strike-slip faulting), will be markedly different not 
only from a region with fabrics that are characteristic of a normal or a reverse fault block regime, but also will be totally different, depending on whether the strike-slip origin was extensional or compressional when originally created, (refer to the complexity shown in Figure $2-$ a typical strike-slip domain). Although this generalisation holds true only for the latest event structural fabric, ideally the regional geology around a project site should be very carefully evaluated using cartoons such as Figure 2 to highlight complications that have been introduced with each structural overprint. Specific care must, however, be taken to understand the controlling structural fabric age relationships, as overprinting of newer structures may obliterate or significantly alter earlier structure, resulting in complex conditions that need to be carefully unravelled, particularly where the same features have been reactivated by subsequent eras of deformation.

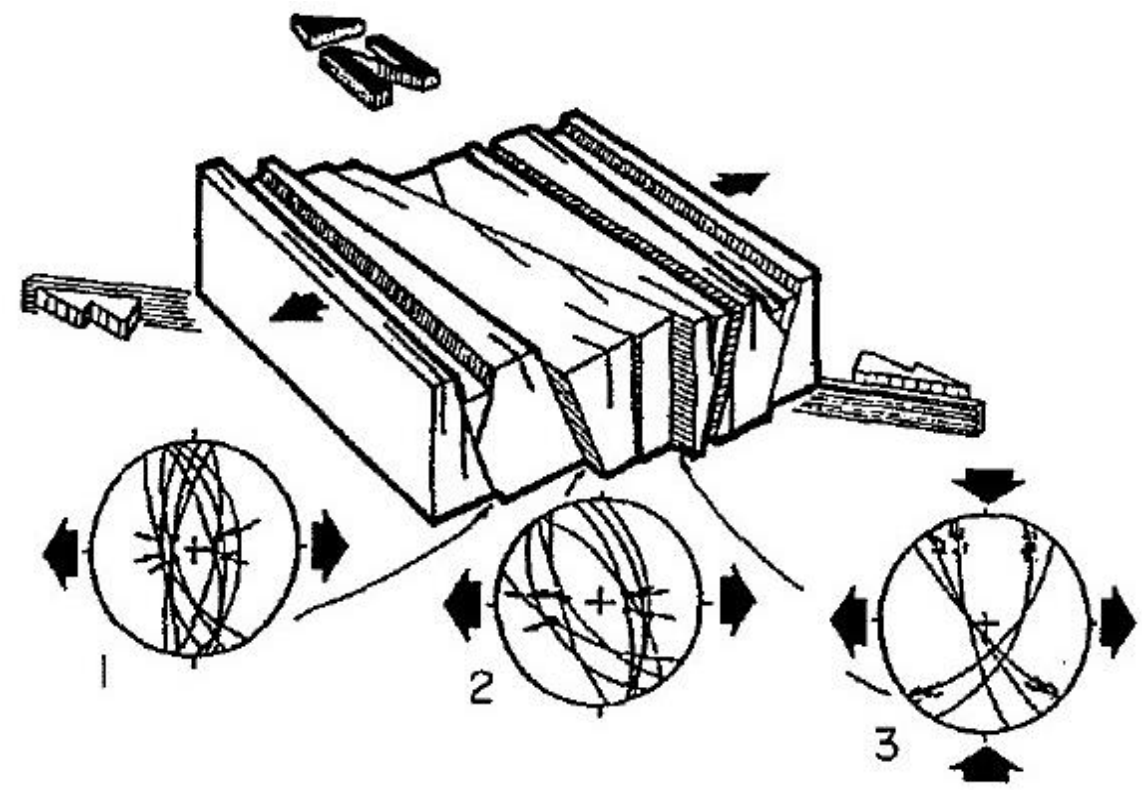

Figure 2 Fabrics related to extensional right lateral normal (dextral) strike-slip faulting (after Angelier 1994)

\subsection{Mining experience}

For more than four decades, rock mass classification approaches have dominated underground and surface characterisation for design in the mining industry as the sole basis for collection of basic data needed for stope or pit scale engineering designs. The earliest mining modifications to the basic civil tunnelling rock mass classifications occurred within the first years following publication of the landmark papers on RMR (Bieniawski 1973) and Q (Barton et al. 1974) with the earliest examples published in the late 1970s and early 1980s being the well-known Laubscher's (1977) underground mining RMR (MRMR) version and the Mathews method (Mathews et al. 1981) using Q prime, without the stress and water components of the Q-system. An open pit version of RMR was similarly developed around the same time by Robertson (1988), Romana (1985) and Romana et al. (2003). These approaches revolutionised data collection and heralded a change from solely carrying out graphical geological mapping and documenting symbolically the dips and strikes of structures to, in the extremes, merely collecting numerical parameter data with no actual map generated as part of the raw data acquisition phase.

Geological mapping and plotting of discontinuities ceased to be the mainstream, with pit and underground data collection being categorised by cell mapping for pits and by blast round face mapping for underground drifts. This focus on cell or grid mapping and stepwise data collection, together with the widespread use of block modelling techniques in exploration (for grade evaluation), which then morphed to rock quality designation or RMR block modelling evaluation, has particularly suited the industry's transition to heavy use of codes such as FLAC and FLAC3D (Itasca Consulting Group, Inc. 2015) which slice and dice the rock mass into small cubes which arguably allow rock mass variability to be better assessed than was ever possible before classification and cell mapping methods were introduced. 
This process towards defining the characteristics of the large scale by building models from millions of ever smaller blocks has almost reached a zenith in the synthetic rock mass models being generated from tiny particles within programs such as Itasca's particle flow code (Sainsbury et al. 2008). But while significant insight on occasion has been gained by use of these models, as they often allow the microphysics to be explored in much more detail than was hitherto possible, they need extensive and careful calibration in order to ensure they are appropriately replicating the reality of natural processes (Kaiser et al. 2015; Carter 2015a). But something has been lost in this transition over the last four decades - and that is simply (1) the basic understanding of the structural mechanics of a given project's situation within the larger-scale tectonic framework, and (2) its implication for mining adjacent to and through faulted ground.

As a general rule, mine project staff, even most ground control engineers, no longer have the same in-depth understanding of the juxtaposition of structure with mine infrastructure as their predecessors had before the advent of 'mapping by numbers'. In other words, the clarity of understanding has gone down with heavy use of classifications rather than graphical geologic data plotting.

One problem that is systemic now is that it is no longer possible to go back to the drift and mine maps where only classifications have been logged and ascertain why a particular failure had occurred, why a particular zone is more problematic than another, or even establish what sort of structure was actually encountered. This is not, infrequently, because no maps have been generated - only the numerical classification values per round or cell length have been recorded.

The problem of lack of insight is further compounded by the fact that the trend today is to immediately investigate a particular problem that develops by resorting to modelling the zone of concern, often with insufficient hard data to actually create a credible model. Much of the intuitive understanding of previous generations of ground control engineers, who had been exposed to routine round by round hand methods of mapping, has been lost. In fact, while perhaps the number of failures of small to medium scale has, over the years, been reduced significantly, perhaps due to the more rigorous matching of installed rock support to rock mass characteristics, mainly because of use of discrete cell or domain based classification approaches, the number of larger scale failures has not diminished. In fact, in recent years, arguably the number of significant large failures has actually increased, perhaps proportionally with the ever increasing depth and size of mined openings.

It is this larger-scale problem to which the remainder of this paper is addressed. However, for the sake of brevity, and particularly as details of several of the most recent very large-scale mining failures remain under confidentiality constraints due to legal ramifications, the following sections deal only with the simple structural techniques that the authors feel should be more widely applied. Principally a rejuvenation of structural geological mapping is needed to help improve insight and give back to ground control engineers everywhere some of the intuitive judgement of their predecessors lost in the transition to reliance on numerical parameter classification zoning and numerical modelling as the main, perhaps often sole, basis for support and mine planning decision making.

As examples for where these techniques typically have application, some case record examples are cited from the literature and from within companion papers on the same theme (in particular Carter (2015b) and Carter \& Valley 2013). While not exhaustive, it is hoped that the case record citations included in these referenced papers, plus some key bibliography related to the three techniques discussed subsequently, will allow the reader access to sufficient background material to gain understanding from the introductory outlines presented in this paper. It is stressed, however, that application of the suggested techniques should be applied in concert with renewed emphasis on proper graphical structural geological mapping being again undertaken routinely as part of the standard suite of data collection information that the industry sees as necessary for acquisition for all future mining projects.

There is a need to re-awaken intuition in the current generation of ground control engineers in order to improve understanding of potential adverse mechanisms, so as to help reduce the risk of more unexpected large scale failures occurring in the future. A fine balance must be maintained between analysis (as the basis for improved understanding) and intuition/judgement that the analysis results are correct. 
Unfortunately, the level of intuition necessary to critique the very latest, most sophisticated program code output results can only be gained by years of experience - and solid understanding of the potential failure mechanisms and the geological processes controlling such mechanisms.

However, merely taking the necessary steps to carry out the simple techniques suggested in the next sections of this paper will not only force an improvement in the collection of basic structural geological data, it will also significantly help improve basic mechanics understanding, and hence intuitive reasoning will, in turn, be enhanced in the process. One major benefit of applying these simple techniques, and perhaps moving to even better overall structural geological assessments for future projects, is that their application will necessitate acquisition of slip sense data that is rarely, if ever, routinely collected as part of even sophisticated mining geotechnical investigations.

If this simple extra step of a return to graphical mapping and to collecting all three key measurements on any identified fault planes can become the new standard for field data acquisition it is hoped this will help focus future investigation, and plotting and evaluation approaches.

Unfortunately, this is going somewhat counter to current industry trends, which are moving more and more towards abandoning personnel doing field structural mapping and documenting characteristics of joints and faults in diagrams and plans as part of raw data collection. Rather, recommendations are prevalent in the literature nowadays that technical personnel should be transitioning to only defining joint fabrics through software interrogation of LiDAR or photogrammetrically collected point cloud data.

The improved quantum of data that can be quickly and accurately collected using these techniques with the software auto-picking dip and dip direction data by triangulation interpretation from within the point cloud information defining the shape of the rock surfaces is commendable, but it must be accompanied by (a) field inspection of the condition of the joint and fault surfaces; and (b) for the latter, by measurement of stria or lineation orientations and gouge and infill characteristics, so that movement sense can be properly and reliably determined, and significance of mechanism on adjacent sympathetic fabric can be appreciated.

\section{$3 \quad$ Key mechanisms}

The probable formational principal stress orientations for the three main types of fault structure have been recognised and well documented since the 1950s (Anderson 1951), viz. normal, with the major principal stress axis generally sub-vertical; thrust (or reverse) with the major principal stress axis sub-horizontal and at right angles to the strike of the fault plane, and strike-slip or wrench mechanisms, with the major principal stress oriented sub-parallel to the strike of the faults (Figure 3 ).

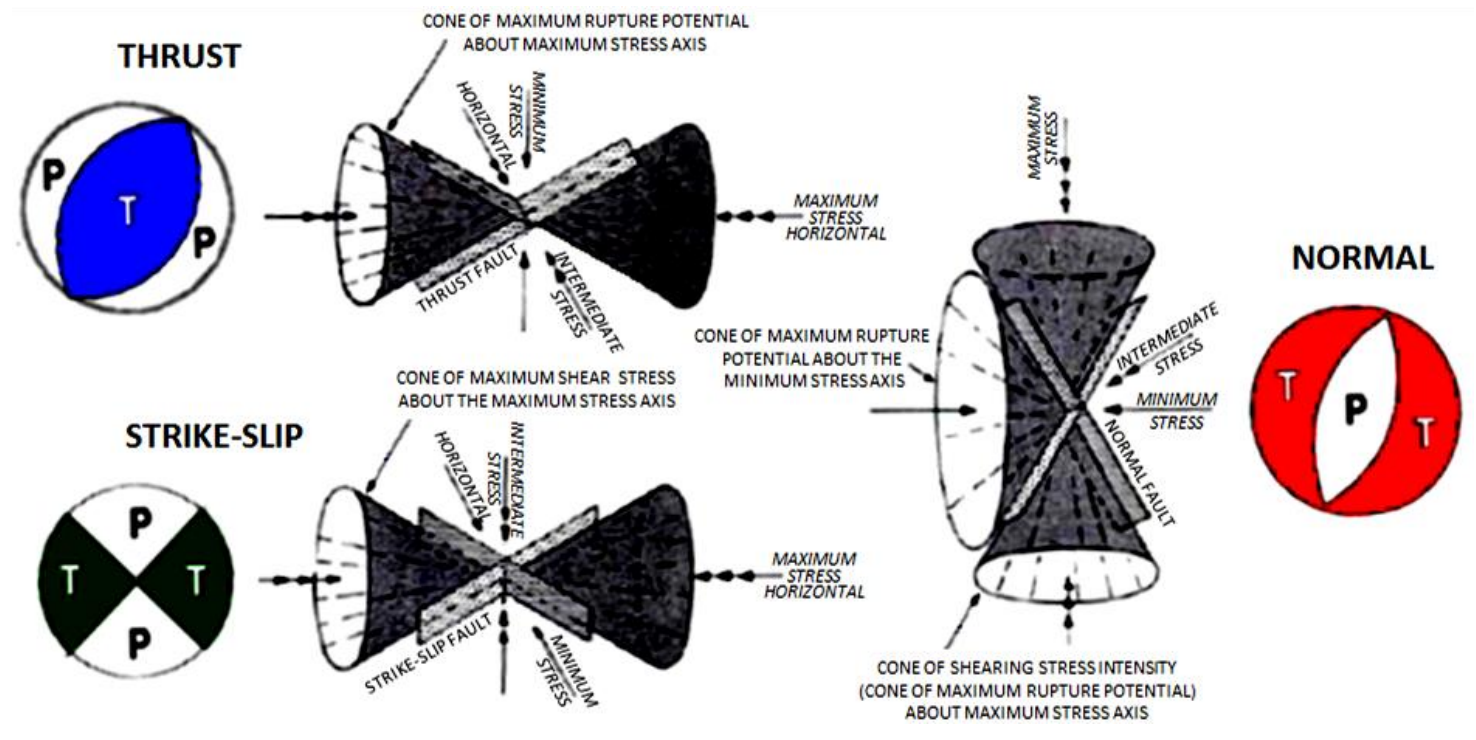

Figure 3 Definition beachball plots and characteristic cones of possible location for major principal stress with respect to shear directions (after Badgley 1959) 


\subsection{Simple diagnostic indicator approaches}

\subsubsection{Beachballs}

In Figure 3, the three cones of possible orientation of the principal stresses are shown for each of the classic Andersonian fault fabrics alongside characteristic colour-coded beachball plots for each of the mechanisms ( red $=$ normal, blue $=$ reverse (thrust) and green $=$ strike slip). These diagrams can be readily constructed by drawing the inferred fault plane on the stereonet and then plotting the auxiliary plane on the sphere perpendicular to the fault plane and the striae. The great circle for the fault plane, plus this auxiliary plane, then create four right dihedra, or quadrants; two of them are bisected by the P-axis (the maximum compressive quadrants).

The $\mathrm{x}$ and $\mathrm{y}$ coordinates for the great circle arcs plotted on these diagrams for an equal angle stereographic projection in two-dimensional space for the fault and auxiliary plane are described by the following Equations 1 and 2:

$$
\begin{aligned}
& x=-R^{*} \tan \xi_{d} * \sin \alpha_{d}+\left(R / \cos \xi_{d}\right) * \cos \beta \\
& y=-R^{*} \tan \xi_{d} * \cos \alpha_{d}+\left(R / \cos \xi_{d}\right) * \sin \beta
\end{aligned}
$$

where:

$$
\begin{aligned}
& R=\text { circle radius. } \\
& \xi_{d}=\text { dip angle of the fault. } \\
& \alpha_{d}=\text { dip direction. } \\
& \beta \quad=\text { variable from } 0 \text { to } 2 \pi .
\end{aligned}
$$

Kinematically, the maximum principal stress has to lie within the two maximum compressive quadrants (Figure 3). The other two (i.e. the minimum compression quadrants) are bisected by the T-axis, while the line of intersection of the fault and the auxiliary plane is termed the neutral or B-axis. Taken together these three ( $\mathrm{P}-, \mathrm{T}-\mathrm{and} \mathrm{B}-)$ orthogonal directions define the kinematic axes, which are aligned sympathetically with the principal stress axes $\sigma_{1}, \sigma_{3}$ and $\sigma_{2}$ respectively. These same beachball diagrams for normal and reverse fault configurations are repeated within Figure 4 alongside characteristic block model geometry diagrams for both of the fault types. Strain rosette diagrams and Mohr circle plots are also shown for the characteristic controlling stress state for these two characteristic 'end member' fault mechanisms.
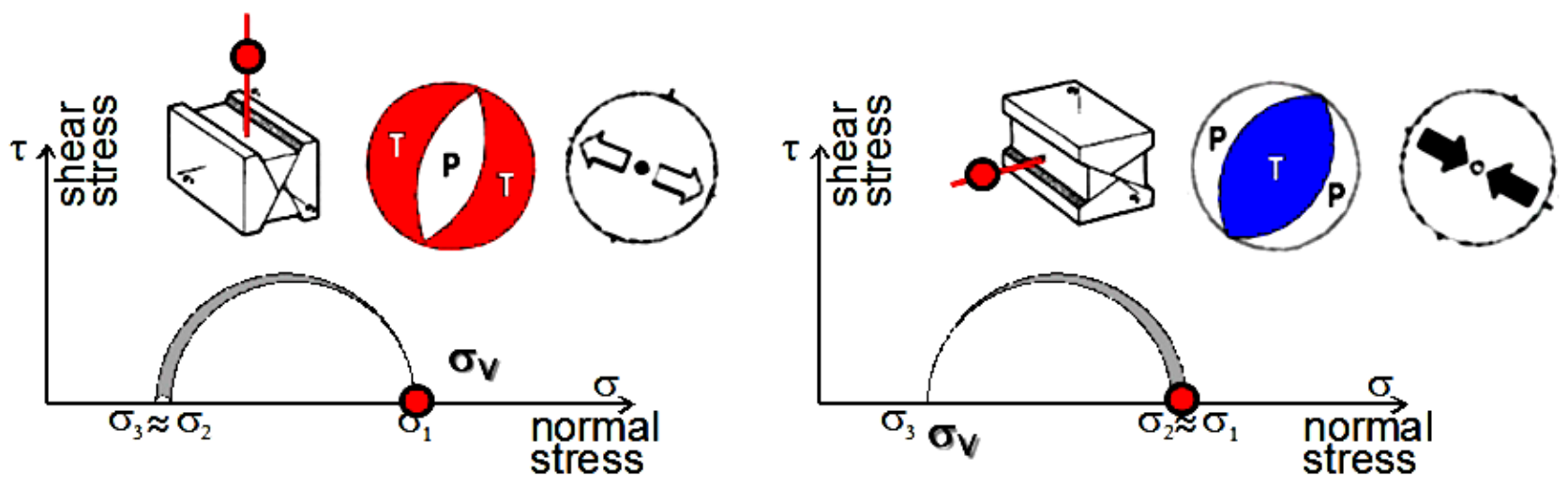

Figure 4 Classic fabrics and faults associated with tensional and/or compressional stress states

Once one becomes familiar with what these beachball diagrams portray, it becomes relatively easy to relate their geometry to the classic ideal Andersonian fault models (refer to the inset block diagrams in Figure 4 for normal and reverse stress states). Similarly, equally diagnostic geometries can be developed for any intermediate (oblique) structural orientation, as illustrated in Figures 5 and 6. 


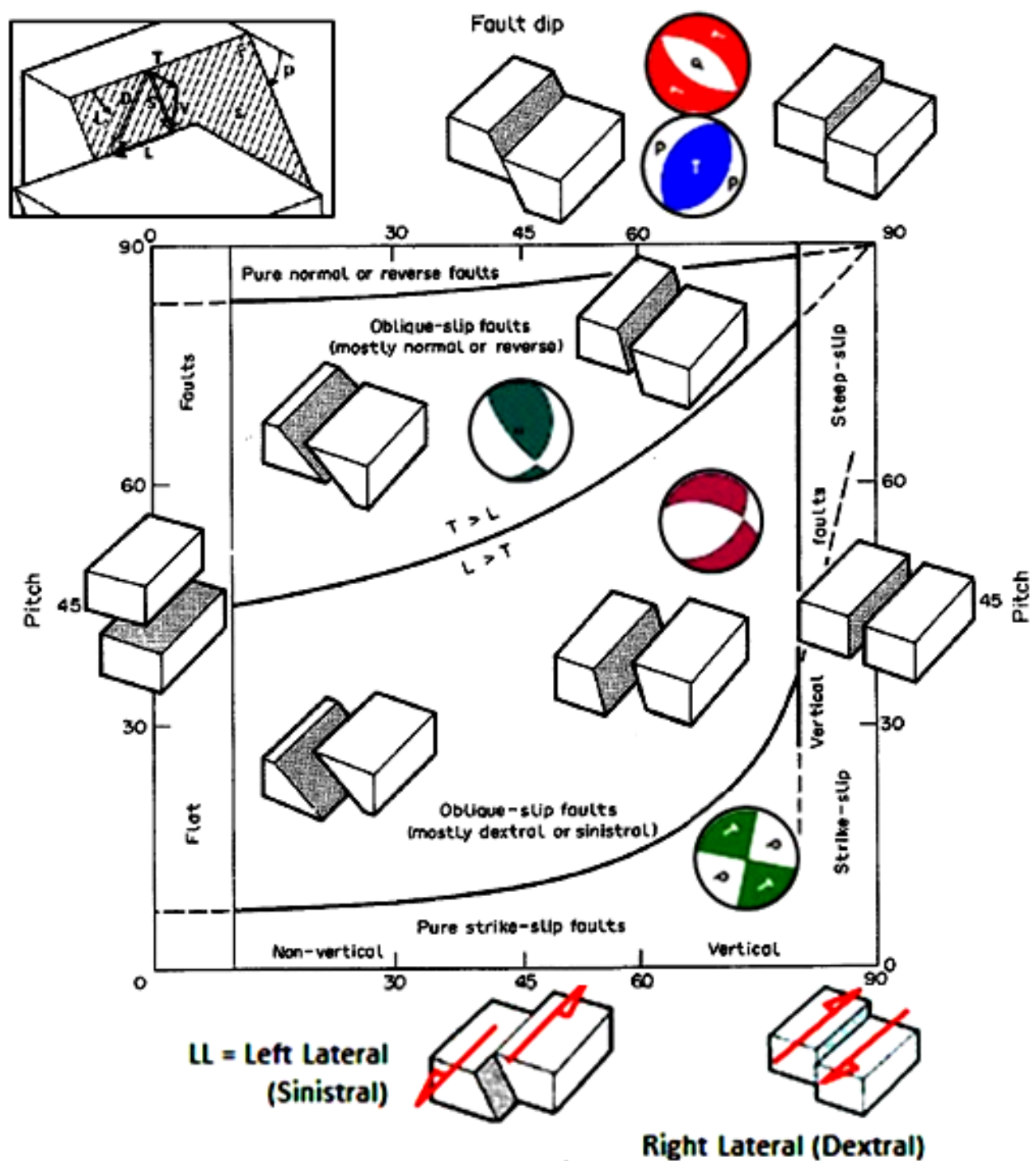

Figure 5 Classification of faults based on fault dip and pitch of slickenside lineation (dip of fault plane $=\mathrm{P}^{\circ}$, pitch of lineation $=\mathrm{I}^{\circ}$ (ref. key sketch diagram in top left of figure, where $D=$ total displacement, $\mathrm{S}=$ downslope slip, $\mathrm{L}=$ lateral offset, $\mathrm{T}=$ transverse offset and $\mathrm{V}=$ vertical fault offset) (from Carter \& Bewick 2011, after Angelier 1994)

However, notwithstanding their value for visualisation, it must be realised that except in the ideal situations shown in Figures 3 through 6, such diagrams plotted from striae or palaeostress data, rarely, if ever, define actual principal stress orientations. Although the kinematic axes are usually quite close, they seldom in reality match exactly with principal stress axes directions, as real stress situations are never ideal.

Despite this, in the framework that they are representative of prevailing stress directions, they nevertheless do allow rapid visualisation of the characteristic deformation regimes implied by a given fault/striae dataset (i.e. normal, reverse or strike-slip fault geometry). Beachball plots historically have not been widely used in engineering projects, possibly partly because of concerns that have grown up (mainly in the geological literature) regarding their inaccuracies as indicators of current stress state and general worry about palaeostress providing useful indications of current controlling stress state, with much emphasis being put on collecting and processing sufficient data to make the assessment worthwhile. 


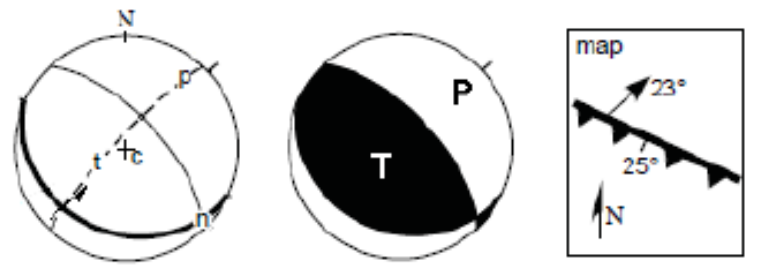

EXAMPLE geometry - orientation directions wrt. reference NORTH Fault dip $25^{\circ}$ dip direction $205^{\circ}$; Lineation plunge $23^{\circ}$ trend $047^{\circ}$

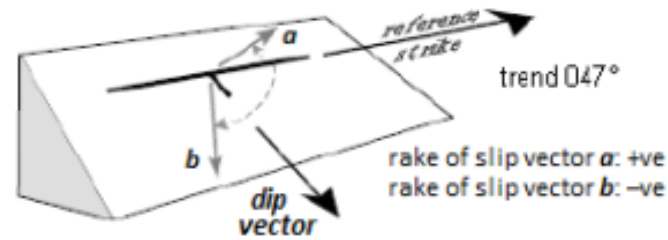

\begin{tabular}{|c|l|l|}
\hline Rake of Slip & \multicolumn{1}{|c|}{ Fault Type } \\
\hline $0^{\circ}$ or $180^{\circ}$ & & pure strike-slip \\
\hline $90^{\circ}$ & & pure dip-slip reverse \\
\hline$-90^{\circ}$ & & pure dip-slip normal \\
\hline$-20^{\circ}$ to $20^{\circ}$ & & left-lateral strike-slip \\
\hline $20^{\circ}$ to $70^{\circ}$ & & reverse left-lateral oblique \\
\hline $70^{\circ}$ to $110^{\circ}$ & & reverse \\
\hline $110^{\circ}$ to $160^{\circ}$ & & reverse right-lateral oblique \\
\hline$-160^{\circ}$ to $160^{\circ}$ & & right-lateral strike-slip \\
\hline$-110^{\circ}$ to $-160^{\circ}$ & & nomal right-lateral oblique \\
\hline$-70^{\circ}$ to $-110^{\circ}$ & & nomal \\
\hline$-20^{\circ}$ to $-70^{\circ}$ & & noma1 left-lateral oblique \\
\hline
\end{tabular}

Figure 6 Relationship between beachball dihedra plots and traditional outcrop mapping designations of classic fault type for specific rake angles of measured striae (after Carter \& Bewick 2011, modified from Cronin 2010)

This literature recognises that with information from one fault only, and without reliable striae data, it is impossible to resolve the stress state accurately. Hence, often it seems there is general reluctance to even try the techniques since, as discussed subsequently, they could potentially be erroneous. Rather than just using them as indicators to guide intuition and understanding, debate continues citing issues of inter-fault stress rotation effects where shear sense within individual blocks within a package of faults may not match a simplistic Andersonian model, and thus could lead to wrong inferences being made. These discussions just detract unnecessarily from use of dihedra plots as simple summation diagrams to guide insight.

As complicated situations are, in general, the exception rather than the norm, it is suggested that for first levels of assessment the general reliability of the Anderson model of rigid block faulting and of the Wallace-Bott hypothesis (Wallace 1951; Bott 1959) that shear sense is always in the plane of the major principal stress, be accepted as reasonable assumptions. This then makes it possible to make quite sensible deductions about prevailing stress and shear sense history and formational characteristics of specific fault features simply by plotting beachball (dihedra) diagrams. Accuracy of the defined stress orientations must, however, always be considered approximate, as actual faults seldom precisely conform with the full suite of the Wallace-Bott assumptions, namely that (1) slip on fault surfaces always parallels the applied shear stress, (2) faults are always planar, (3) blocks are always rigid, (4) no stress perturbations nor block rotations occur along fault surfaces, and (5) the applied stress state always remains uniform during any single tectonic event (represented by the shear striae). More recent work by Lisle (2013) suggests that the error band in defined palaeostress orientations will always be within about $\pm 25^{\circ}$, even for extreme corrugations and angularity on fault surfaces, which is good enough for most initial mining analysis assumption purposes.

There are some situations, however, where particular care must be taken, but for most other situations if half a dozen or more fault striae data intersections can be found, and analysed, sufficient insight can be gained from applying even the simplest of these approaches. One of the cases often cited as problematic involves situations where a card pack of en echelon parallel faults exist on a specific project site. Because of their parallelity, often reverse senses of shear can be found in field exposures. Accordingly, such faults need to be carefully evaluated on a structure by structure basis, and some of the advanced techniques suggested by Allmendinger et al. (1989) and by Jackson and McKenzie (1988) need to be applied in order to ensure that the most probable generating stress domain is established.

It must always be appreciated that in all real cases, there are inevitable issues of detail that must be unravelled. Nevertheless, if even the simplest of the approaches outlined in this paper are applied more generally in the mining industry, this insight might immeasurably increase understanding of ongoing stress driven fault-slip failure mechanisms. Stress rotation is of particular importance for underground mining and 
could partially at least have been responsible for creating the necessary shear domains that controlled some of the larger burst events reported in recent years. Use of these techniques might help in establishing particularly prone orientations for slip. Also their application may help in definition of precursors.

One of the simplest techniques to estimate palaeostress orientations is the right dihedra method described by Angelier and Mechler (1977). This graphical method is based on the idea that orientation of the maximum principal stress axis is constrained to the pressure $(P)$ quadrant, while orientation of the minimum principal stress axis is constrained to the tension (T) quadrant associated with a chosen fault. As shown on Figure 7, if enough overlapping fault solutions can be generated the location position of the inferred stress orientations becomes quite well constrained.

The interested reader should experiment with these right dihedra (P-T) techniques and also with the M-method of Arthaud (1969) and the right trihedra method of Lisle (1987) which arguably is less ambiguous in defining the tectonic axes (Lisle et al. 2001). These and other methods have been programmed into codes such as T-Tecto (Žalohar \& Vrabec 2007; Žalohar 2012) and TectonicsFP (Reiter \& Acs 2002).

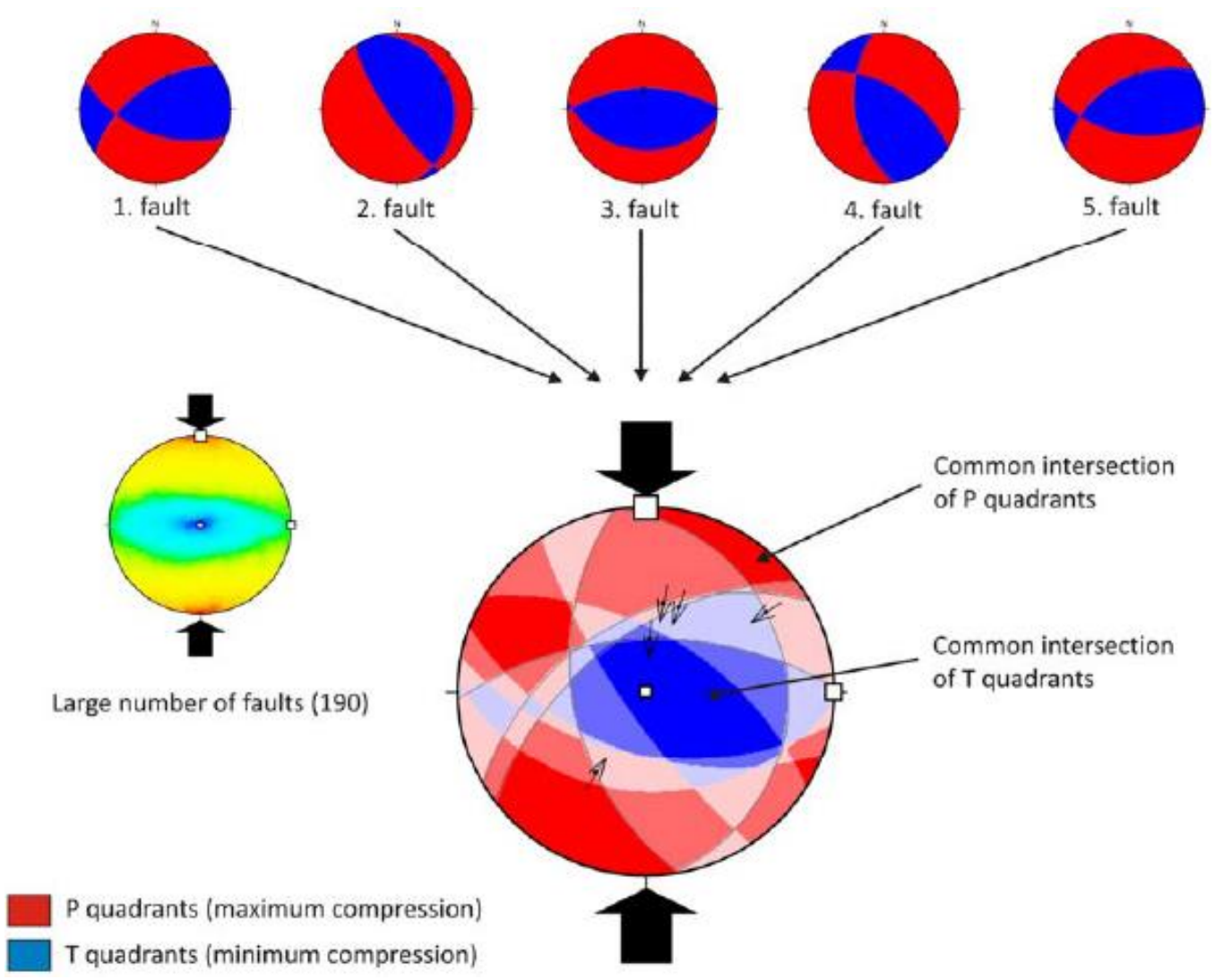

Figure 7 Application of the right dihedra method for assessing palaeostress orientations (Žalohar 2009)

\subsubsection{Ternary diagrams}

Single beachballs are excellent for looking at a few faults, but often there is a need to summarise many faults on a mine-wide or project-wide scale. One of the most convenient approaches for summarising such fault orientation information makes use of ternary diagrams plotting the plunge of the principal tectonic axes. As shown in the left diagrams in Figures 8 and 9, in concept ternary diagrams are synthesis plots allowing many faults to be shown so that understanding of fault patterns can be achieved for a given project site. The diagram is configured (Frohlich 2001), such that faults with normal configuration (P-axis vertical) plot in the lower left corner of the diagram, faults with thrust configuration (with P-axis horizontal, normal to the fault plane) plot in the lower right corner of the diagram, and faults with P-axis horizontal, but with T- (or B-) axis vertical plot at the top of the diagram. The zone where characteristic thrust faults 
plot in these diagrams is typically extended out from the lower right apex of the diagram to an arc defined where the plunge of the $\mathrm{P}$ - or $\mathrm{B}$-axis is greater than about $50^{\circ}$. The zones where diagnostic geometry is normal or strike-slip is defined by arcs at the other two apex locations when the plunge of the $\mathrm{T}$ - or $\mathrm{B}$-axis is greater than $60^{\circ}$.

The diagrams in Figures 8 and 9 are plotted using the azimuthal gnomonic projection, for which horizontal and vertical distances $\mathrm{Hg}$ and $\mathrm{Vg}$ from the central point of the equatorial triangle of height, $H$, are given by Frohlich (2001), as shown in Equations 3 and 4:

$$
\mathrm{Hg}=\mathrm{H} \sqrt{2} \cos \delta_{\mathrm{B}} \sin \psi\left[3\left(\sin \theta_{0} \cdot \sin \delta_{\mathrm{B}}+\cos \theta_{\mathrm{o}} \cdot \cos \delta_{\mathrm{B}} \cos \psi\right)\right]
$$

and

$$
\mathrm{Vg}=\mathrm{H} \sqrt{2}\left(\cos \theta_{\mathrm{o}} \cdot \sin \delta-\sin \theta_{\mathrm{o}} \cdot \cos \delta_{\mathrm{B}} \cos \psi\right) /\left[3\left(\sin \theta_{\mathrm{o}} \cdot \sin \delta_{\mathrm{B}}+\cos \theta_{\mathrm{o}} \cdot \cos \delta_{\mathrm{B}} \cos \psi\right)\right]
$$

where $\sin ^{2} \delta_{T}=\sin ^{2} \delta_{B}=\sin ^{2} \delta_{P}=1$ and $\psi$ is set such that $\psi=-45^{\circ}+\tan ^{-1}\left(\sin \delta_{T} / \sin \delta_{P}\right)$ and $\theta_{0}=$ the plunge of each of the principal axes. The exact centre of the diagram, by definition, given this is an equilateral triangle, represents a state where each of the principal tectonic axes is at the same identical plunge of $35.26^{\circ}$, i.e. $\theta_{0}=\sin ^{-1}\left(1 / 3^{1 / 2}\right)$. Faults that plot towards the centre of the diagram thus diverge significantly from the three classic Anderson modes - and represent more the transpressional or transtensional mechanisms illustrated in the centre of Figure 5. These same transpression and transtension zones are plotted with an oblique hatch symbol in both diagrams in Figure 8.

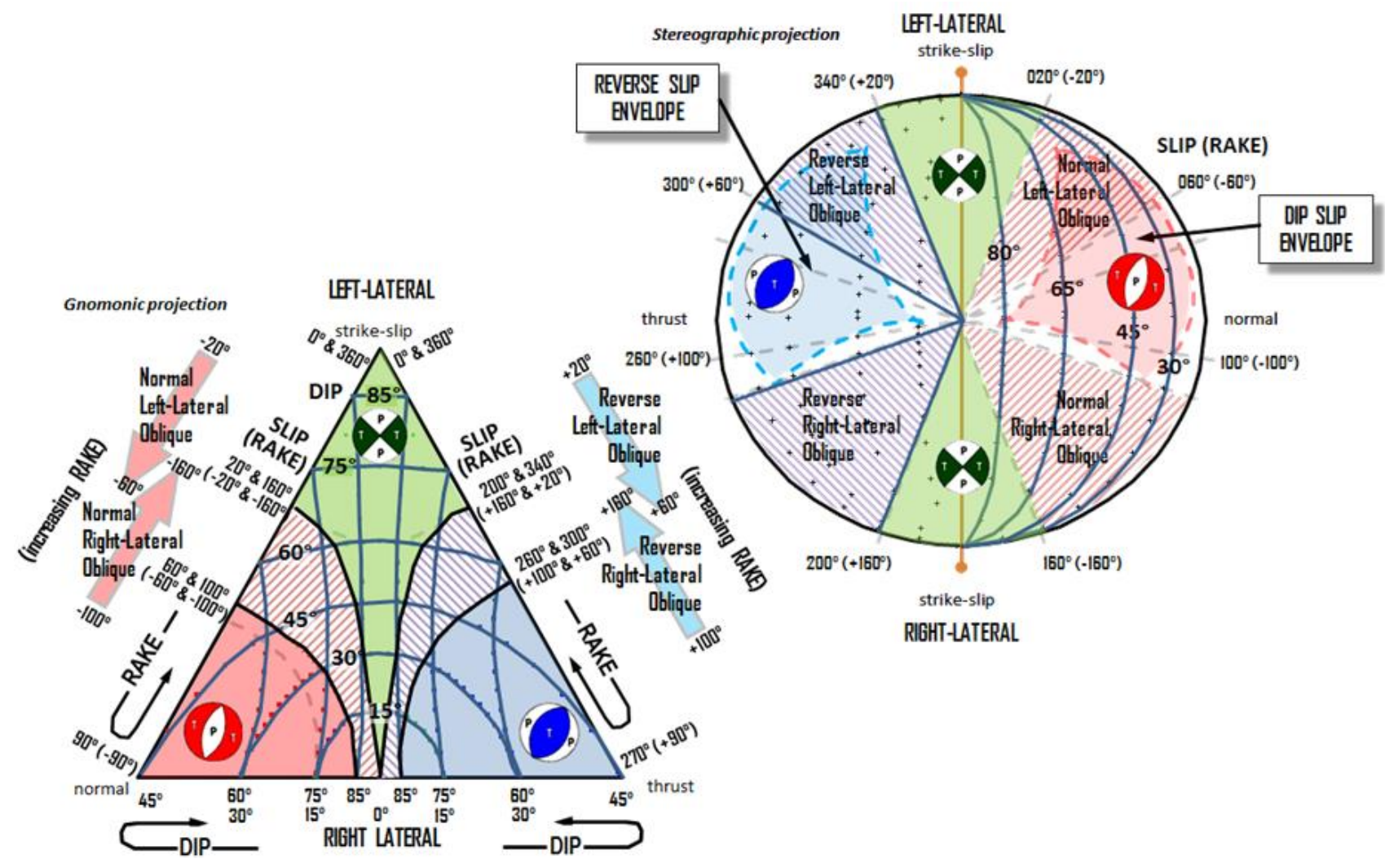

(a)

(b)

Figure 8 Relationship of ternary diagram with rose diagram, showing key fault mechanisms and geometry (rakes per table in Figure 6). (a) azimuthal gnomonic projection ternary plot (Frohlich 2001), overlaid with rake and slip scales and fault definition zones; and (b) compass rose showing same dips and rakes as plotted on diagram (a)

Note that envelopes of inferred normal and reverse faulting on rose diagram based on plunge of principal tectonic axes in the ternary diagram differ slightly from normally accepted ranges (as tabulated in Figure 6). 
In Figure 8, the relationship of the various classic fault dips and rakes which define fault geometry as intrinsically incorporated into the construction of the ternary diagrams have been delineated and dip and rake lines have been drawn as an overlay over the diagram. This has been done to allow direct relationships of fault geometry to be more readily matched to the more familiar standard compass rose representation of fault attitude (Figure $8(\mathrm{~b})$ ). The great advantage of the ternary diagrams though is in analysis of a fabric of different faults. They can be used like contoured stereonets to synthesise fault characteristics and aid determination of what may be the controlling fault regime. They also help highlight possible palaeostress orientations of concern for mining reactivation of shear on the faults. Some indication of the possible geometry of the full palaeostress stress tensor can also be approximated given some evaluation of the likely controlling stress ratio based on the inferred tectonic axes, as plotted on the ternary diagram, (refer to Carter \& Valley 2013 for example plots for a variety of mining environments). These fault regimes can also be evaluated further to back-out the most likely stress states, using Mohr circle plots such as incorporated into Figure 9 for aiding unravelling of possible stress states for most fault mechanics.

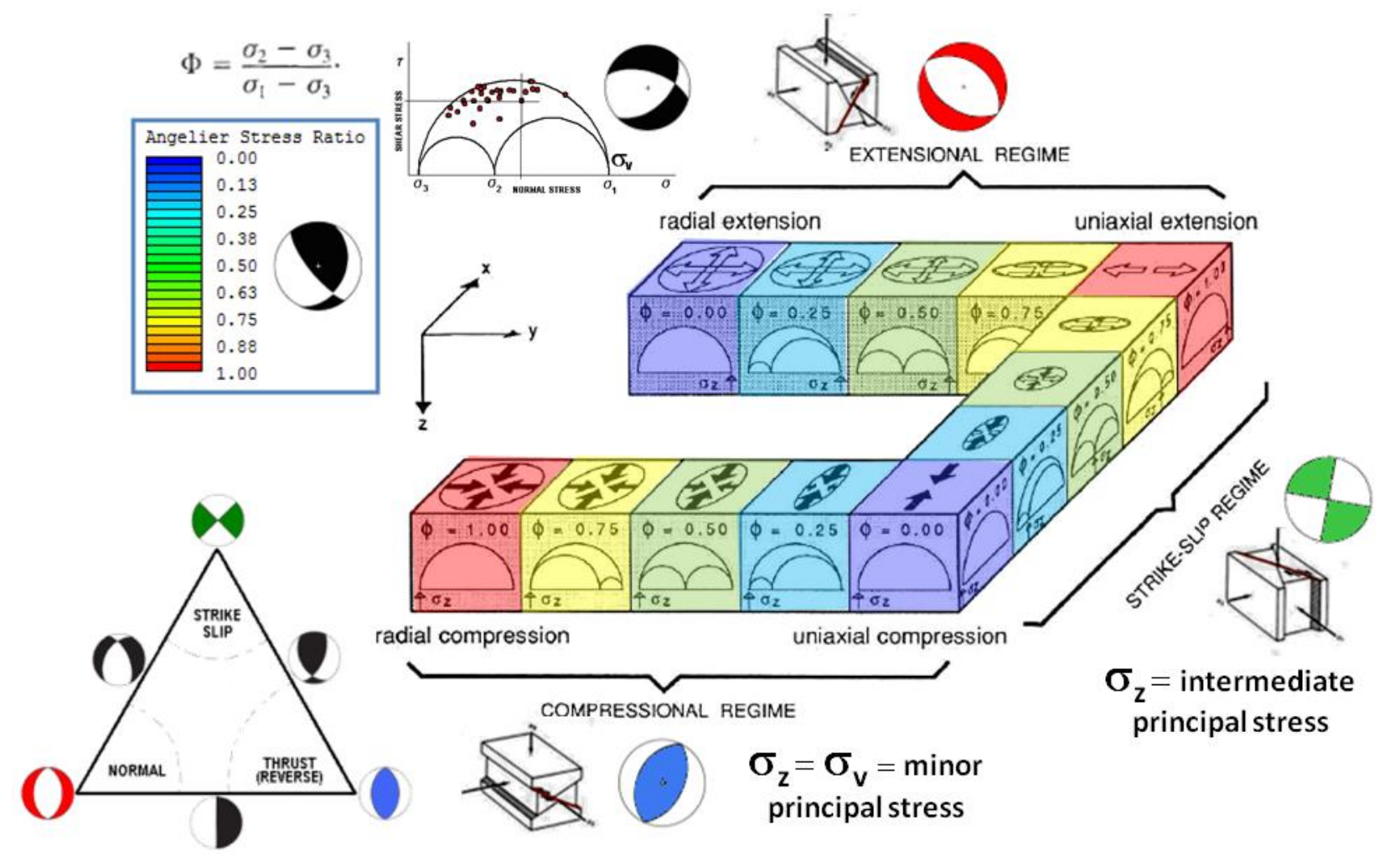

Figure 9 Classification of different tectonic stress states for different Fault geometries as plotted from beachballs and ternary diagrams, after Carter (2015b) (with key inset diagram modified from original created by Ritz 1994)

\subsection{Slip tendency evaluation}

\subsubsection{Stereonet approaches}

While the palaeostress inversion approaches inherent in plotting beachballs and ternary diagrams allows one to look backwards based on existing fault characteristics as a means to estimate possible ancient controlling geologic stress states, often one also wishes to do the opposite - and identify those faults and structures that might become a problem when stress states become altered - as for example often happens in a mining situation, for which the insight gained from examination of Figure 9 can be beneficial.

The slip tendency analyses approach outlined below provides this corresponding forward projection solution in contrast to the backward looking palaeostress inversion approach. The methodology discussed below was originally introduced by Morris et al. 1996, as a method to evaluate the relative potential for 
fault activity to occur given a specific stress state. It is based on the assumption that faults are cohesionless interfaces and their re-activation occurs when the resolved shear stress on the fault plane, $\tau$, exceeds the frictional resistance to sliding, which is a function solely of the resolved normal stress on the fault plane on.

The slip tendency, Ts, is then defined as: $T s=\tau / \sigma_{n}$. Given that the potential slip direction and sense tends to be driven by the direction and sense of the resolved shear stress on a given fault it is instructive to contour values of slip tendency on a stereographic projection, such as is shown in the diagrams in Figure 10. This is one of the most useful approaches for visualising adverse fault orientations. When presented on the stereonet, the pattern of slip tendency does not depend of the actual stress magnitude, but only on the orientation of the principal stress axes and the ratio of those principal stresses, which is classically plotted in terms of $\Phi=\left(\sigma_{2}-\sigma_{3}\right) /\left(\sigma_{1}-\sigma_{3}\right)$ (Angelier 1994), as shown also in the colour scales included within Figure 9 .

As is evident from Figure 10, the higher the shear stress relative to the normal stress on the fault plane, the higher the propensity for the fault to slip. For non-extreme cases, including the case where $\Phi \approx 0.5$, the critical orientation for potential slip is well defined by a unique conjugate set of planes, but when $\Phi$ reaches the extreme limits of 0 or 1 the orientations prone to slip cover a wide range of geometries, describing a complete cone with respect to the stress directions, all with equal slip propensity.

Once stereonet plots have been prepared, it is simple to evaluate what fault orientations relative to the principal stress directions are the most prone to slip. The geometry of the principal stresses for different stress ratio $\Phi$ magnitudes can then be readily derived from Figure 9, knowing the characteristic beachball plot geometries for the various types of faults.
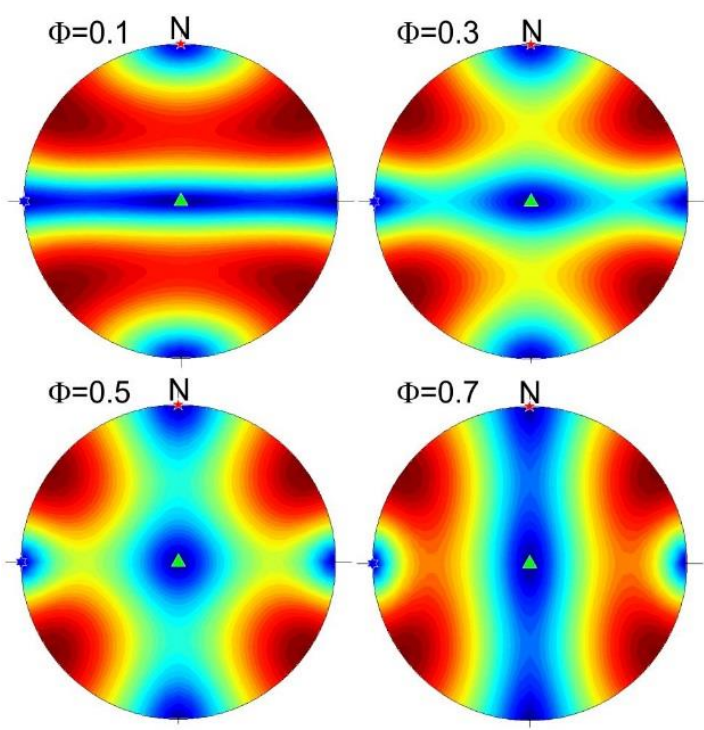

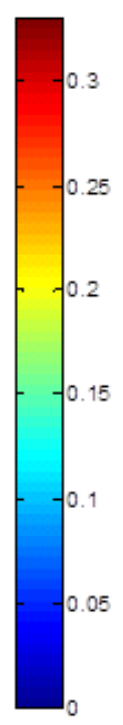

Figure 10 Example slip tendency patterns on the stereonet (lower hemisphere, equal area). Right diagram shows $45^{\circ}$ dominant shear for subvertical major principal stress $\sigma_{1}$ (red, five-pointed star) with horizontal N-S, intermediate stress $\sigma_{2}$ (green triangle) and horizontal, approximately E-W minor stress $\sigma_{3}$ (blue, six-pointed star). Left diagram illustrates patterns for various stress ratios $\Phi$ and for a strike-slip stress regime - with vertical intermediate stress, $\sigma_{2}$ (green triangle) with horizontal N-S major $\sigma_{1}$ and E-W minor $\sigma_{3}$ principal stresses, (from Carter \& Valley 2013)

\subsubsection{Boundary element fault modelling}

These same slip tendency analysis approaches can be utilised to contour the surfaces of faults that cross a mining block and could be influenced by any stress changes induced by mining. Figure 11 , which has been prepared using boundary element modelling of a fault crossing a mining block simulated by a discrete discontinuity plane, shows a typical example of a slip tendency plot not just for the natural in situ stress state, but also for the state post excavation. The influence of the excavation of the drift on the fault, although small in terms of differential slip, is noticeable. 

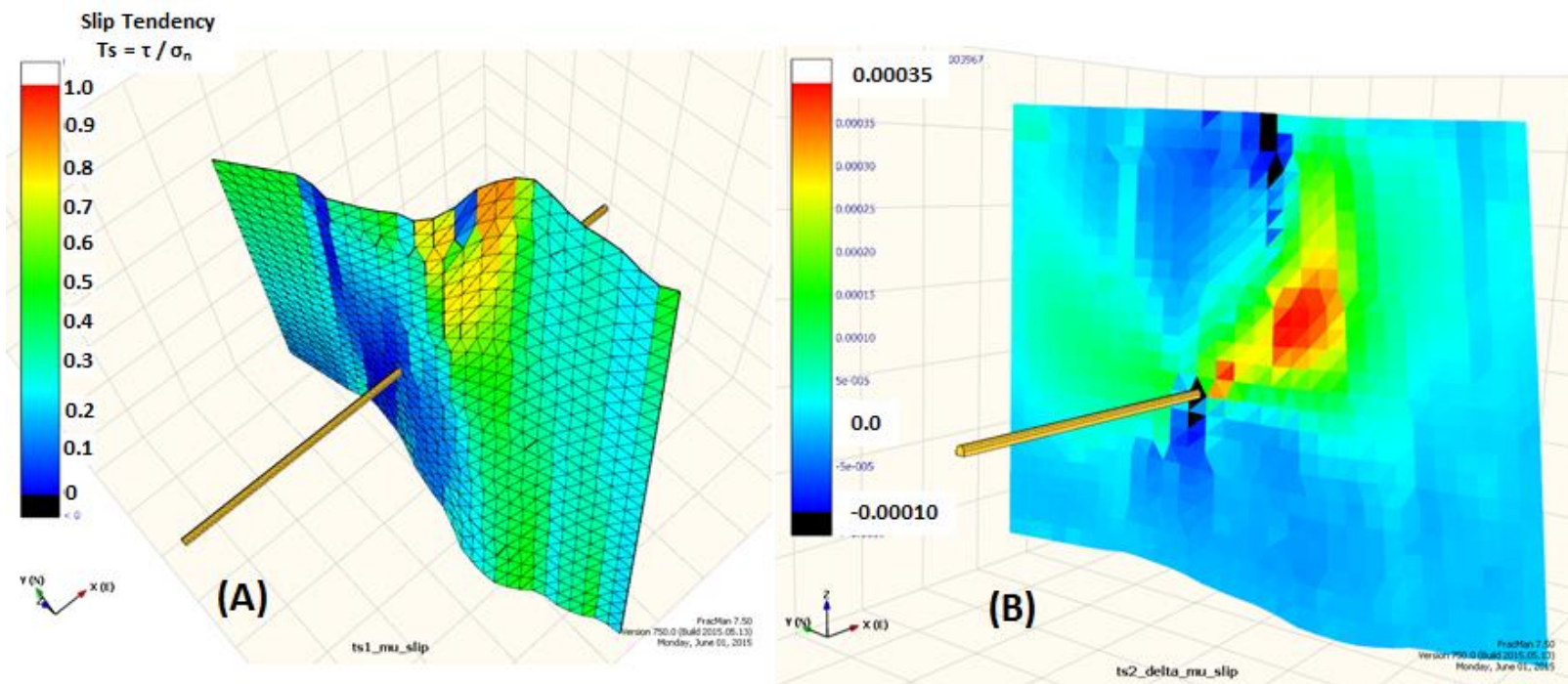

Figure 11 Differential slip induced by drifting through a sub-vertical fault in a typical mine situation:

(a) pre-mining slip tendency; and (b) differential slip induced on the fault as a result of the excavation of the drift through the fault

Given the characteristics and extent of the zone of induced differential shear (slip) for even such a minor excavation penetration, much more significant influence might be expected for larger scale mining in close proximity to this particular fault. Generation of this type of plot for different production mining simulations would therefore be recommended to aid in identifying regional and localised potential problem zones associated with mining through such a fault. Depending on the complexity of the geometry being evaluated 2D and 3D boundary element codes such as Examine 2D (Rocscience 2014) and Map3D (Wiles 2014) have applicability, as both have facility for modelling fault slip tendency.

Mine-wide, patterns of faulting can exert a significant influence on mining approaches. Preparation of plots such as Figure 12, which shows a more regional pattern of faulting such as might exist across a deep mine property footprint, have merit for mine planning as such plots can help in deciding best extraction directions and helping in targeting hot spots where ground control problems might be expected.

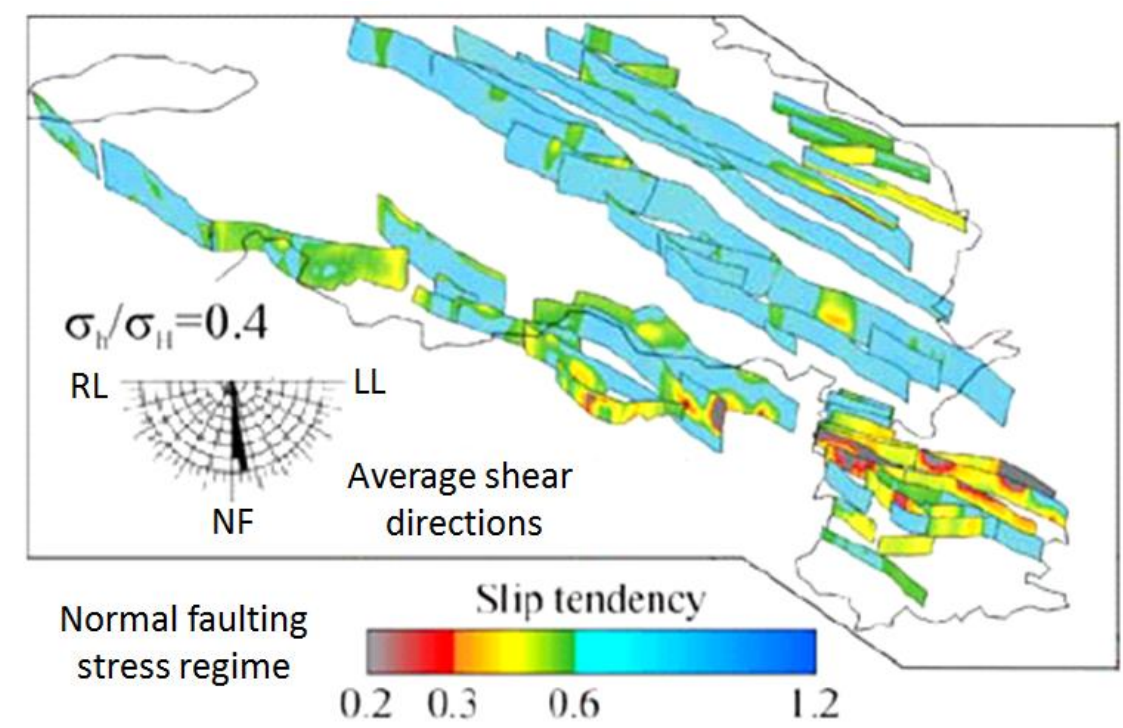

Figure 12 Example regional scale slip tendency plot for inferred normal faulting stress regime showing zones of most probable reactivation (modified from Worum et al. 2004) 
In this case, there is a marked propensity for normal fault regime reactivation in the more south easterly corner of the mining block, given certain assumptions for the ratios of the horizontal principal stresses.

The application of the slip tendency approaches discussed above to assess fault influence as part of a mine planning modelling exercise can be extremely beneficial for helping obviate significant unexpected ground control problems that might arise in later mining stages. These techniques have been sporadically used in the mining industry (Board 1994; Castro et al. 2009; Wiles 2014), but are not regularly employed, which is a deficiency that, as mines go ever deeper, needs to be addressed.

\subsection{Critical stress concept}

An adjunct to the techniques presented above, which helps define the orientation and position of the most likely stress-driven fault reactivation zones, is to check the induced mobilisation state conditions against the most probable strength state of the faults considered of concern, by applying the critical stress concept.

\subsubsection{Mohr circle plots}

Mohr circles have been used to display the state of induced normal and shear stress on geological structures for many years, e.g. Jaeger and Cook (1984). However, it was Barton et al. (1995) who first used the term critically stressed fractures to describe discontinuities considered prone to shear. They applied the term 'critically stressed' to those fractures whose ratio of shear to normal stress fell in excess of a particular failure criteria. Their work was primarily aimed at identifying fractures and faults in the sub-surface that were likely to be experiencing enhanced permeability as a result of shear failure resulting in fracture dilation, the widening of aperture and consequently increased flow capacity. However, exactly the same methodology can be applied to structural slip analysis for application in a mining context.

Assuming that both the magnitude and orientation of the stress field has been defined, then the resultant shear $(\tau)$ and normal stress $\left(\sigma_{n}\right)$ experienced on a fracture surface (Jaeger \& Cook 1984), can be calculated from Equations 5 and 6 as follows:

$$
\tau=\beta_{11} \cdot \beta_{21} . \sigma_{1}+\beta_{12} . \beta_{22} . \sigma_{2}+\beta_{13} \cdot \beta_{23} . \sigma_{3}
$$

and

$$
\sigma_{\mathrm{n}}=\beta_{11^{2}} \cdot \sigma_{1}+\beta_{12^{2}} \cdot \sigma_{2}+\beta_{13^{2}} \cdot \sigma_{3}
$$

where $\beta_{\mathrm{ij}}$ are the directional cosines between the fracture surfaces and the stress tensor, and $\sigma_{1}, \sigma_{2}$ and $\sigma_{3}$ are the magnitudes of the maximum, intermediate and minimum stress components.

In order to display this stress and orientation data, a three-dimensional (3D) Mohr diagram needs to be used. When considering borehole data and mine wide data, in general it should be borne in mind that the magnitudes of each of the stresses likely will increase with depth. Thus, in order to allow all of the data from the same borehole or from multiple holes or locations within the full geometry of a mine to be plotted within the same data space of the Mohr circle, all of the data needs to be normalised with respect to the vertical stress component.

Figure 13 shows an example of the graphical method for representing the state of stress on all fractures within an in situ stress field, where the propensity would be for thrust faults to dominate field conditions.

In this plot, points plotting above and to the left of the assumed shear failure criterion line would be likely the most problematic and perhaps would then be able to be singled out for further study. 


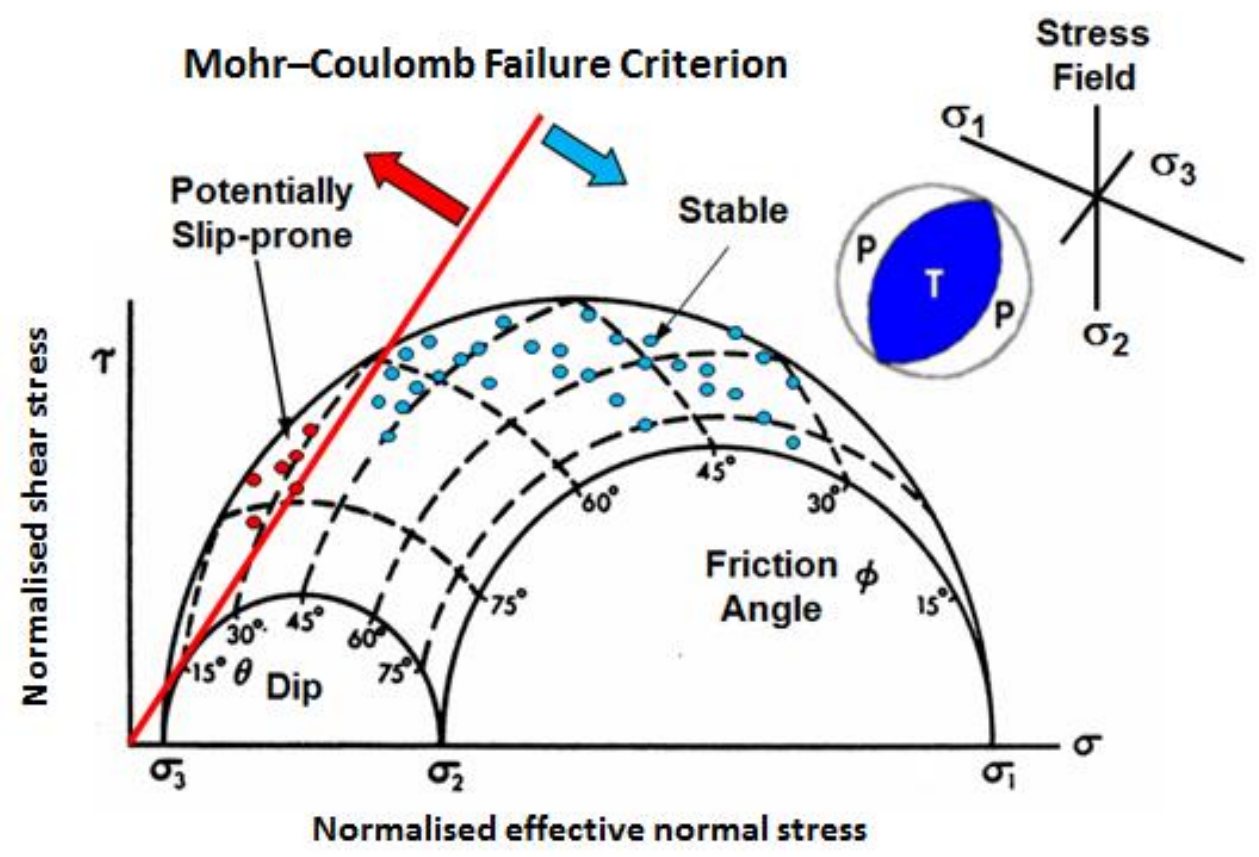

Figure 13 Example critical stress plot for induced shear on major discontinuities (including faults) within a mining block with respect to induced shear strength on structures. A site-specific failure criterion is added to test whether the fracture surface is in or close to a state of failure. Barton et al. (1995) use the Mohr-Coulomb failure criterion, although a Barton-Bandis model (Barton \& Bandis 1982) can equally be used

\subsubsection{Stereonet plots}

The magnitude of induced shear and normal stress across a structure is controlled by the orientation of the structure and the local stresses relative to the in situ or mining-induced stress field. Therefore, the fault slip potential (the ratio of shear/normal stress) can be calculated for all orientations and plotted stereographically as a polar plot, with the data contoured with respect to the stress ratio with actual mapped or logged fracture orientations plotted on top as poles (see Figure 14, top right). As with Figure 10, the redder (hotter) colours in the NW and SE quadrants of the plot represent zones of higher shear/normal stress ratio and therefore, fault structures with poles falling in these zones would be more likely to slip.

In the case shown in Figure 14, which represents a strike-slip stress regime with a maximum horizontal stress aligned at approximately $40^{\circ}$, it is clear to see that there are four main orientations that cause the highest ratios of shear/normal stress. These correspond to fracture and fault surfaces striking in distinct directions: one runs approximately north-northeast to south-southwest with the second trending approximately east-northeast to west-southwest.

As expected, the structures with the greatest fault slip potential are those critically stressed ones, orientated with strikes approximately $\sigma_{H \max } \pm 30^{\circ}$, as also illustrated by the shaded zones included in the lower right diagram.

Figure 14 (bottom right diagram) also shows the borehole fracture orientations coloured by whether they are critically stressed or not (as also shown on the main Mohr circle diagram), with the zones of red, critically stressed fractures ringed also, and the green, stable fractures not. Note that the population of critically stressed fractures represents a relatively small subset of the total population corresponding to those fractures plotting above the mid failure criterion line.

Of course, critical stress analysis does not have to be carried out as a static analysis on discrete structures in an initial in situ stress field. 
By integrating the analysis with a total stress field (magnitudes and directions) as derived from numerical analysis of a mining sequence, the degree to which structures become more prone to failure during mining life can be viewed. This evaluation can be carried out for individual fault structures or more generically looking at full joint fabrics.

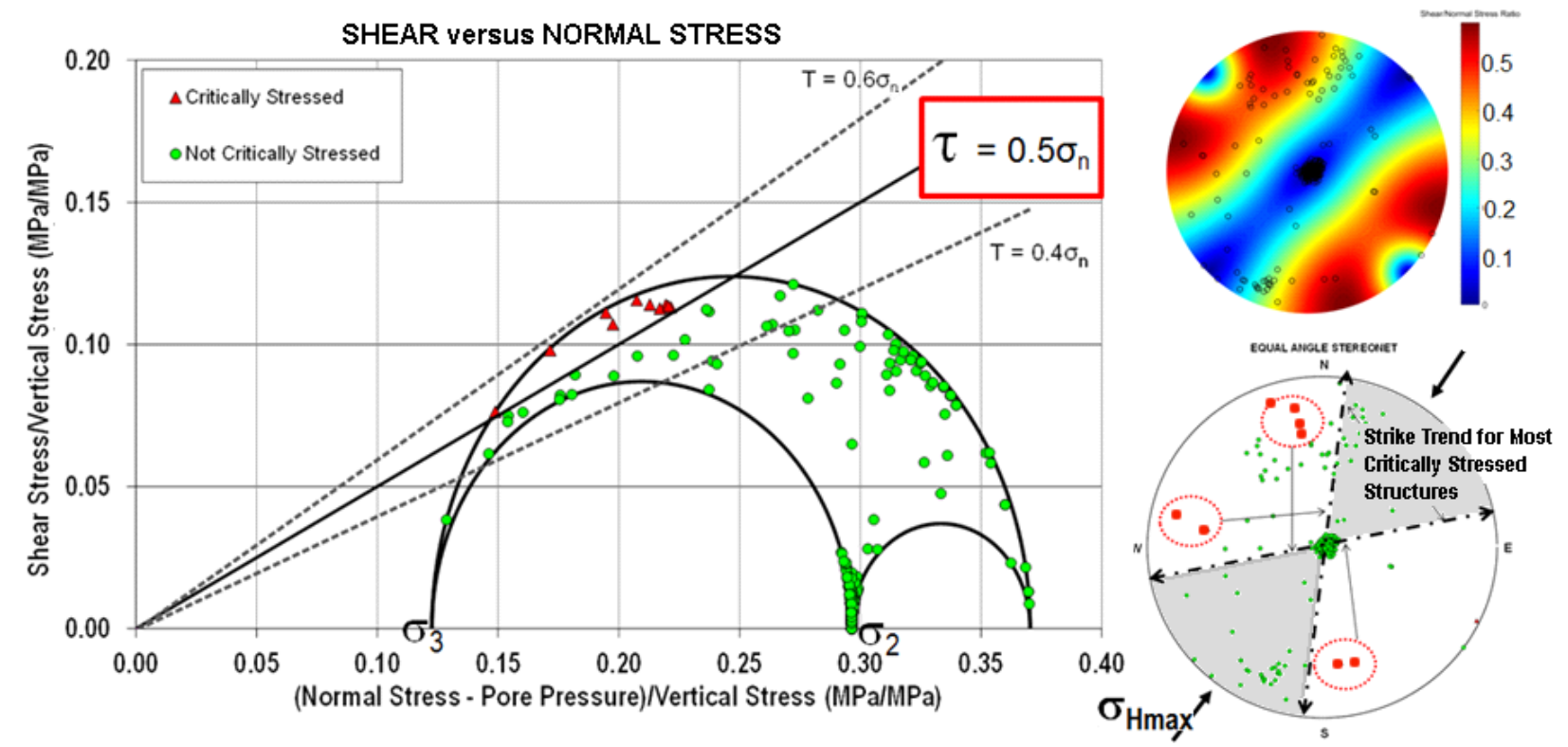

Figure 14 Critical stress plot for assumed shear strength assumptions, with stereonet of structures and slip tendency plot illustrating dominant orientation controls

Figure 15 shows the Mohr circle (modified) plots of the state of stress on structures as well as a histogram of fault slip potential from structures within a FracMan ${ }^{\circledR}$ discrete fracture network model (Dershowitz 1995) with the data also displayed stereographically. On the left is the pre-mining state and on the right is the post mining state.

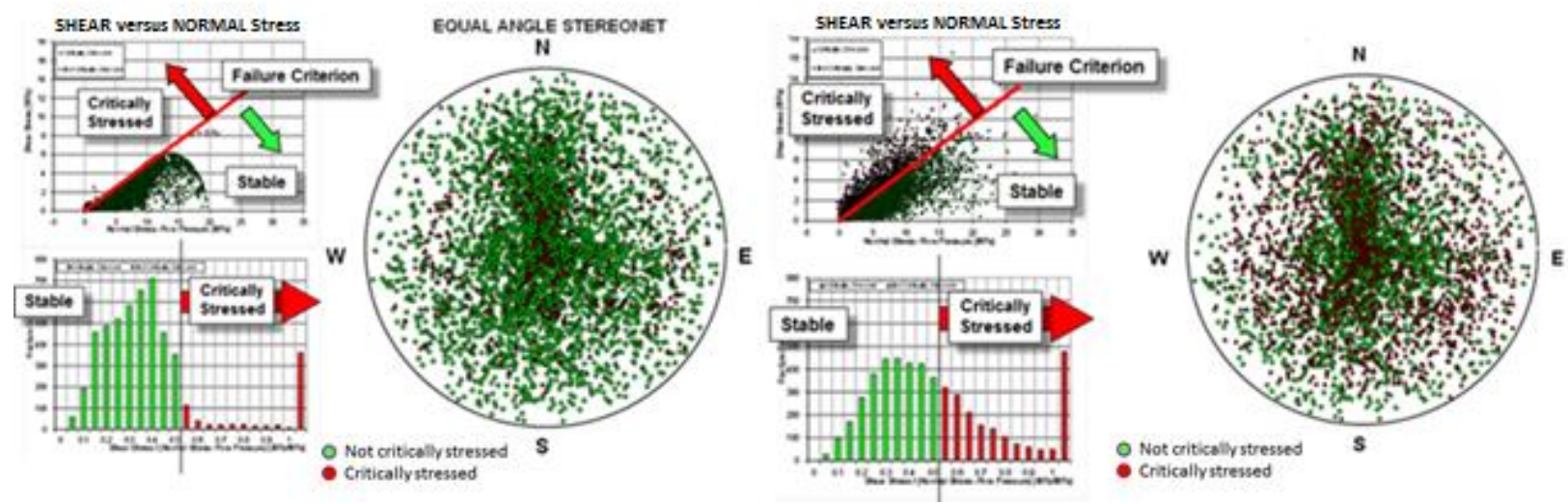

Figure 15 Comparison - pre- and post-mining slip tendency on individual discontinuities within a mining block - green features stable, red features exhibit excess shear

Under pre-mining conditions (left diagrams), just a few structures are critically stressed as seen on the Mohr circle and the histogram (mostly the diagrams are green, only a few red areas are indicated in both where these are critically stressed). As mining advances and the stresses evolve and change direction, an increasing number of structures become critically stressed. Note in particular the change in the post-mining (right hand) histogram compared to the pre-mining state.

Figure 15 only shows the pre- and post-mining conditions but the analysis here has also been carried out for all mining sequence steps to help identify any critical stages in mining where the propensity for fault slip significantly increases. It should also be noticed that there is no actual Mohr circle plotted on the diagram 
showing shear and normal stress. As these data have been extracted from a 3D model grid where the actual stress directions and magnitudes vary in every cell, a unique Mohr circle would be needed for every cell. As such, under these conditions, it is more effective to simply assess fault slip potential against the relevant failure criteria, as has been done in these.

\section{Conclusion}

This paper has attempted to present several structural geology techniques that are not widely known or even commonly applied for deep high stress mining (or even for deep civil engineering design) purposes. However, it is considered that these approaches could be more widely utilised particularly as they can have merit for risk minimisation for deep excavation development.

Several techniques have been explored as a means for assessing the propensity of specific geologic structures to pose risks for deep mining or deep civil projects.

Guidelines for evaluating critical stress state, applying slip tendency assessment methods and for using fault striae data and applying stress inversion approaches have been presented. Example applications of these methods have been outlined as basis for assessing propensity for adverse fault-controlled movement that could be of concern for mining development. Some approaches have also been presented for evaluating probable past and current stress states - both of which are considered key to establishing propensity for re-activating slip on incipient geological structures.

For any given fault of interest, in addition to the control on stress tendency orientation and stress ratio $\Phi$, exerted by the geometry of the situation and the prevailing stress state, the actual magnitude of slip tendency depends on the mean and differential stress magnitudes. In situations where stress states are isotropic, even with relatively high mean stresses, high normal stresses are generated, thus relatively low slip tendencies result. Conversely, in areas where even moderate stress inhomogeneity exists, relatively high differential stresses develop, and thus large shear stresses will be generated and relatively high slip tendency will be computed.

Application of slip tendency analyses to engineering problems is attractive in allowing fairly rapid evaluation of a large number of potential stress ratio scenarios. Initial fault stability can be assessed (assuming only the stress ratio) and as additional constraints on the stress ratio or on stress magnitudes, are collected, these initial analyses can be readily refined.

For deep mines, assessing and back-analysing the geological history of the host area and assessing the characteristics of regional structural faults has merit as a means for estimating likely in situ stress states. Such assessments are feasible way prior to being able to get underground and actually conduct a program to measure in situ stresses. Back-analyses of probable stress state may in fact help project planning and aid the quantifying of risk.

The structural geological and rock mass characterisation methods for appraisal of faults and deep adverse geological structure presented in this paper utilise several techniques that have application for unravelling fault behaviour of importance to deep engineering projects. All of these methods can be relatively easily integrated into the site characterisation toolbox, as collecting the additional data is not particularly onerous. Furthermore, once collected, such data can allow definition of tectonic indicators that might give clues to recent tectonic history and aid evaluation of risk for potential remobilisation.

Application of the suggested methods can also provide insight to unravelling past geologic history and assessing current stress states (prior to mining). Used in conjunction with rock mass classification with GSI or $Q$ approaches, these techniques can allow early recognition and definition of potential adverse mine excavation behaviour that might develop associated with the intersection of significant faulting at depth.

Key geological data of importance to gaining an adequate understanding of controlling structure driving these types of instability problems does not seem to be regularly collected or evaluated. In fact, mostly the industry is unaware of the benefits that can be gained by appropriate use of these simple structural 
geological tools, explored in this paper, which if applied pro-actively could significantly improve insight and understanding of possible interactions and implications. This in turn might better help mines deal with deep structure by allowing ranking of faults - into ones to watch out for, collect more data on, or simply plan for use of enhanced support around them.

\section{Acknowledgement}

Application of the techniques discussed in this paper has fallen into disuse in many parts of the mining industry, partly due to changes in approach to mine planning through more focus on computer based statistical ore reserve estimation, rather than on detailed structural geological mapping and analysis of controlling geological structure with emphasis on examining mining extraction implications.

Several rockbursts in the Canadian mines and a number of large scale open pit failures and underground mine stoping induced failures that have adversely affected surface infrastructure has rejuvenated an interest in application of these old methods to help better understand fault slip. The Centre for Excellence in Mining Innovation (CEMI), in particular Dr Peter Kaiser, Mr Damien Duff and Mr Rob Bewick plus a number of mines are acknowledged for their contribution to this rekindling of interest.

\section{References}

Allmendinger, RW, Gephart, JW \& Marrett, RA 1989, 'Notes on fault slip analysis', Proceedings of the Geological Society of America Short Course on Quantitative Interpretation of Joints and Faults, Cornell University, Ithaca, NY, viewed 1 July 2015, www.geo.cornell.edu/pub/rwa/GSAFaults89.pdf

Anderson, EM 1951, The dynamics of faulting, 2nd edn, Oliver \& Boyd, Edinburgh.

Angelier, J 1994, 'Fault slip analysis and palaeostress reconstruction' in PL Hancock (ed.), Continental deformation, Pergamon Press, Oxford, pp. 53-100.

Angelier, J \& Mechler, P 1977, 'Sur une méthode graphique de recherche des contraintes principales également utilisable en tectonique et en séismologie: la méthode des dièdres droits', Bulletin de la Societe Geologique de France, vol. 19, pp. 1309-1318. [In French]

Arthaud, F 1969 'Méthode de détermination graphique des directions de raccourcissement, d'allongement et intermédiaire d'une population de failles', Bulletin de la Societe Geologique de France, vol. 11, pp. 729-737. [In French]

Badgley, PC 1959, Structural methods for the exploration geologist, Harper, New York, NY.

Barton, CA, Zoback, M \& Moos, D 1995, 'Fluid flow along potentially active faults in crystalline rock', Geology, vol. 23, no. 8, pp. 683-686.

Barton, N \& Bandis, S 1982, 'Effects of block size on the shear behaviour of jointed rock', in RE Goodman and FE Heuze (eds), Proceedings of the 23rd US Symposium on Rock Mechanics (USRMS), American Rock Mechanics Association, Minneapolis, $\mathrm{MN}, \mathrm{pp} .739-760$.

Barton, N, Lien, R \& Lunde, J 1974, 'Engineering classification of rock masses for design of tunnel support', Rock Mechanics and Rock Engineering, vol. 6, no. 4, pp. 189-236.

Bieniawski, ZT 1973, 'Engineering classification of jointed rock masses', Transactions of the South African Institution of Civil Engineers, vol. 15, no. 12, pp. 335-344.

Bieniawski, ZT 1989, Engineering rock mass classifications, John Wiley \& Sons, New York.

Board, M 1994, 'Numerical examination of mining-induced seismicity' PhD thesis, University of Minnesota.

Bott, MHP 1959, 'The mechanisms of oblique slip faulting', Geological Magazine, vol. 96, pp. 109-117.

Carter, TG 1992, 'Prediction and uncertainties in geological engineering and rock mass characterization assessment', Proceedings of the 4th Italian Rock Mechanics Conference, pp. 1.1-1.22.

Carter, TG 2010, 'Applicability of classifications for tunnelling - valuable for improving insight, but problematic for contractual support definition or final design', Proceedings of the World Tunnelling Conference (WTC 2010) and the 36th ITA Congress, section $6 \mathrm{c}, 8 \mathrm{p}$.

Carter, TG 2011 'Himalayan ground conditions challenge innovation for successful TBM tunnelling', Proceedings of the Hydrovision India 2011 Conference, Golder Associates, Toronto, ON, 20 p.

Carter, TG 2015a 'On increasing reliance on numerical modelling and synthetic data in rock engineering', Proceedings of the 13th International Congress on Rock Mechanics, $17 \mathrm{p}$.

Carter, TG 2015b, 'Some geological characterization techniques for assessing fault influence on deep excavations', Proceedings of the 13th International Congress on Rock Mechanics, $11 \mathrm{p}$.

Carter, TG \& Bewick, RP 2011, Structural geological guidelines for aiding characterization of deep mining fault behaviour, Centre of Excellence in Mining Innovation, Sudbury.

Carter, TG \& Valley, BC 2013, 'Application of fault stability analysis techniques for design of deep engineering projects', Proceedings of the 47th US Rock Mechanics/Geomechanics Symposium, American Rock Mechanics Association, Minneapolis, MN, 12 p. 
Castro, LMC, Carter, TG \& Lightfoot, N 2009, 'Investigating factors influencing fault-slip in seismically active structures, in M Diederichs \& G Grasselli (eds), Proceedings of the Third Canada-US Rock Mechanics Symposium and the 20th Canadian Rock Mechanics Symposium (RockEng09), $10 \mathrm{p}$.

Célérier, B, Etchecopar, A, Bergerat, F, Vergely, P, Arthaud, F \& Laurent, P 2012, 'Inferring stress from faulting: from early concepts to inverse methods', Tectonophysics, vol. 581, pp. 206-219.

Cronin, VS 2010, A primer on focal mechanism solutions for geologists (Updated), viewed 1 August 2015, http://serc.carleton.edu/files/NAGTWorkshops/structure04/Focal_mechanism_primer.pdf

Frohlich, C 2001, 'Display and quantitative assessment of distributions of earthquake focal mechanisms', Geophysical Journal International, vol. 144, no. 2, pp. 300-308.

Hoek, E \& Brown, ET 1980a, 'Empirical strength criterion for rock masses', Journal of the Geotechnical Engineering Division, vol. 106, no. 9, pp. 1013-1035.

Hoek, E \& Brown, ET 1980b, Underground excavations in rock, Institution of Mining and Metallurgy, London.

Hoek, E \& Martin, CD 2014, 'Fracture initiation and propagation in intact rock - a review', Journal of Rock Mechanics and Geotechnical Engineering, vol. 6, no. 4, pp. 287-300.

Hoek, E \& Marinos, P 2000, 'GSI: a geologically friendly tool for rock mass strength estimation', Proceedings of the GeoEng 2000 Conference, pp. 1422-1442.

Hoek, E, Carter, TG \& Diederichs, MS 2013, 'Quantification of the geological strength index chart', Proceedings of the 47th US Rock Mechanics/Geomechanics Symposium, American Rock Mechanics Association, Minneapolis, MN, 8 p.

Itasca Consulting Group, Inc. 2015, FLAC3D: Fast Lagrangian Analysis of Continua in 3 Dimensions, versions 7-5, Itasca Consulting Group, Inc., Minneapolis, MN, http://www.itascacg.com/software/flac3d/

Jackson, J \& McKenzie, D 1988, 'The relationship between plate motions and seismic moment tensors, and the rates of active deformation in the Mediterranean and Middle East', Geophysical Journal, vol. 93, pp. 45-73.

Jaeger, JC \& Cook, NGW 1984, 'Fundamentals of rock mechanics, 3rd edn, Chapman \& Hall, London.

Kaiser, PK, Amman, F \& Bewick, RP 2015, 'Overcoming challenges of rock mass characterization for underground construction in deep mines', Proceedings of the 13th International Congress of Rock Mechanics, $14 \mathrm{p}$.

Laubscher, DH 1977, 'Geomechanics classification of jointed rock masses - mining applications', Transactions of the Institute of Mining and Metallurgy, vol. 86, pp. 1-8.

Lisle, R 1987, 'Principal stress orientations from faults: an additional constraint Ann', Tectonicae, vol. 1, pp. 155-158.

Lisle, R 2013, 'A critical look at the Wallace-Bott hypothesis in fault-slip analysis', Bulletin of the Société Géologique de France, vol. 184, no. 4-5 pp. 299-306.

Lisle, R, Orife, T \& Arlegui, L 2001, 'A stress inversion method requiring only fault slip sense', Journal of Geophysical Research, vol. 106, no. B2, pp. 2281-2289.

Marinos, V, Marinos, P \& Hoek, E 2005, 'The geological strength index: applications and limitations', Bulletin of Engineering Geology and the Environment, vol. 64, no. 1, pp. 55-65.

Mathews, KE, Hoek, E, Wyllie, DC \& Stewart, S 1981, Prediction of stable excavation spans for mining at depths below 1,000 metres in hard rock / Golder Associates, CANMET Library \& Documentation Services Division, Vancouver.

Morris, A, Ferrill, DA \& Henderson, DB 1996, 'Slip-tendency analysis and fault reactivation', Geology, vol. 24, no. 3, pp. $275-278$.

Palmström, A 2000, 'Recent developments in rock support estimates by the RMi', Journal of Rock Mechanics and Tunnelling Technology, vol. 6, no. 1, pp. 1-19.

Palmström, A 2005, 'Measurements of and correlations between block size and rock quality designation (RQD)', Tunnels and Underground Space Technology, vol. 20, pp. 362-377.

Palmström, A 2009, Combining the RMR, Q, and RMi classification systems, www.rockmass.net, $25 \mathrm{p}$.

Pollard, DD \& Fletcher, RC 2005, Fundamentals of structural geology, Cambridge University Press, Cambridge.

Potvin, Y, Hudyma, M \& Miller, HDS 1989, 'Design guidelines for open stope support', Bulletin of the Canadian Institute of Mining and Metallurgy, vol. 82, no. 926, pp. 53-62.

Ramsay, JG \& Lisle, RJ 2000, 'Fault slip analysis and stress tensor calculation', The techniques of modern structural geology: applications of continuum mechanics in structural geology, Academic Press, London, vol. 3, pp. 785-810.

Reiter, F \& Acs, P 2002, Tectonics FP software for structural geology, version 1.6, http://www.tectonicsfp.com/

Ritz, JF 1994, 'Determining the slip vector by graphical construction - use of a simplified representation of the stress tensor, Journal of Structural Geology, vol. 16, no. 5, pp. 737-741.

Robertson, AM 1988, 'Estimating weak rock strength', Proceedings of the SME Annual Meeting, Society for Mining, Metallurgy \& Exploration, Englewood, CO, preprint no. 88-145, 5 p.

Rocscience 2014, Examine2D - 2-Dimensional plane strain boundary element program for elastic stress analysis of underground excavations software with slip tendency update, version 8.0, Rocscience, Toronto, ON, https://www.rocscience.com/ help/examine2d/webhelp/examine2d/Examine2D_Overview.htm

Romana, M 1985, 'New adjustment rating for application of the Bieniawski classification to slopes', Proceedings of the International Symposium on Role of Rock Mechanics, International Society for Rock Mechanics, Salzburg, pp. 49-53.

Romana, M, Serón, JB \& Montalar, E 2003, 'SMR Geomechanics classification: Application, experience and validation ISRM 2003Technology roadmap for rock mechanics', Journal of the Southern African Institute of Mining and Metallurgy, pp. 981-984.

Sainsbury, B, Pierce, M \& Mas Ivars, D 2008, 'Analysis of Caving Behaviour Using a Synthetic Rock Mass -Ubiquitous Joint Rock Mass Modelling Technique, in Y Potvin, J Carter, A Dyskin \& R Jeffrey (eds), Proceedings of the First Southern Hemisphere International Rock Mechanics Symposium (SHIRMS), vol. 1 - Mining and Civil, Australian Centre for Geomechanics, Perth, pp. 243-254. 
Wallace, RE 1951, 'Geometry of shearing stress and relation to faulting', The Journal of Geology, vol. 59, no. 2, pp. 118-130.

Wiles, T 2014, 'Three ways to assess mining-induced fault instability using numerical modelling', Proceedings of the 6th South African Rock Engineering Symposium (SARES), The Southern African Institute of Mining and Metallurgy, Johannesburg, $13 \mathrm{p}$.

Worum, G, van Wees, J-D, Boda, G, van Balen, RT, Cloetingh, S \& Pagnier, H 2004, 'Slip tendency analysis as a tool to constrain fault reactivation: a numerical approach applied to three-dimensional fault models in the Roer Valley rift system (southeast Netherlands)', Journal of Geophysical Research, vol. 109, 16 p.

Žalohar, J 2009, T-TECTO 3.0 professional integrated software for structural analysis of fault-slip data, University of Ljubljana, Ljubljana.

Žalohar, J 2012, 'Cosserat analysis of interactions between intersecting faults; the wedge faulting', Journal of Structural Geology, vol. 37, pp. 105-123.

Žalohar, J \& Vrabec, M 2007, 'Paleostress analysis of heterogeneous fault-slip data: the Gauss method', Journal of Structural Geology, vol. 29, pp. 1798-1810. 